\title{
Do Otolaryngology Patients Show Gender Preference When Choosing a Surgeon? - A Quantitative and Qualitative Analysis
}

\author{
Chandala Chitguppi ${ }^{1}$ Tripti Brar ${ }^{1}$ \\ ${ }^{1}$ Department of Otorhinolaryngology and Head and Neck Surgery, \\ Jaypee Hospital, Noida, India \\ Int Arch Otorhinolaryngol 2018;22:404-407.
}

\author{
Address for correspondence Chandala Chitguppi, MBBS, MS \\ (ORL-HNS), Department of Otorhinolaryngology and Head and Neck \\ Surgery, Jaypee Hospital, Noida 201301, India \\ (e-mail: dr.chandala.chitguppi@gmail.com).
}

\begin{abstract}
Keywords

- bias

- sexism

- otolaryngology

- male

- female

Introduction Otorhinolaryngology has always been considered a gender-neutral specialty, whereas in several other specialties, such as obstetrics, gynecology and urology, gender preference has been consistently shown by patients when choosing their treating surgeon. To date, no study has been performed to analyze whether this practice of gender preference is prevalent in otorhinolaryngology patients too.

Objectives To identify if gender preference exists in the field of otorhinolaryngology, specifically in its four subspecialties, namely otology, pediatric otolaryngology, laryngology and head and neck surgery.

Methods Patients attending our outpatient department were asked to complete a preformed proforma. The pro forma consisted of two parts, demographic details of the subjects and gender preference in the following subspecialties: otology, pediatric otolaryngology, laryngology and head and neck oncosurgery.

Results A total of 1,112 subjects took part in the study, out of which 1,089 subjects were included in the final analysis. Female gender preference was highest in the field of pediatric otolaryngology, while male preference was highest for head and neck oncosurgery.

Conclusion Though otorhinolaryngology and head and neck surgery has been considered a gender-neutral field, subspecialties of this field show considerable gender preference.
\end{abstract}

\section{Introduction}

Selecting the right health care provider is a complex task for any patient. In addition to the clinical acumen of the provider, several other variables, such as type and location of the treating center, acceptance of insurance, efficiency and attitude of support staff, also play a role. An unsatisfied patient who is being treated medically may frequently change his/her treating physician. However, once a patient undergoes a surgery, this option is no more feasible. The choice of his/her treating surgeon is unchangeable. There- fore, choosing the treating surgeon can be a source additional stress for some patients. In addition to the clinical acumen, a few patients in search of their 'ideal surgeon' may give undue emphasis to non-clinical characteristics, such as gender, race and religion of the surgeon.

On the contrary, for some patients who are contemplating surgery, these non-clinical variables may be of no significance. As a health care provider, a surgeon is usually associated with a patient for a short duration of time, unlike a family physician, who is involved in the long-term care of received

August 23, 2017

accepted after revision

December 21, 2017

published online

April 12, 2018
DOI https://doi.org/

10.1055/s-0038-1641165. ISSN 1809-9777.
Copyright $\odot 2018$ by Thieme Revinter

Publicações Ltda, Rio de Janeiro, Brazil
License terms

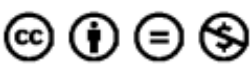


patients and their families. Therefore, a few patients may consider only the surgical expertise of the surgeon when making a selection.

In either scenario, the gender of a surgeon is an immutable variable. Various studies have been conducted to analyze the effect of surgeon's gender in gender-sensitive fields. ${ }^{1-3}$ However, a gender preference analysis in a relatively genderneutral specialty, such as otorhinolaryngology and head and neck surgery (ORL-HNS), has never been conducted. This study is an attempt to assess the effect of the surgeon's gender on patient's preference in different subspecialties of ORL-HNS.

\section{Materials and Methods}

\section{Study Set Up}

This study was conducted in a super specialty hospital situated in suburbs of Noida, India. The hospital caters to both the urban population and nearby rural areas. The department of ORL-HNS consists of almost an equal number of male and female surgeons. Both walk-in patients and patients with prior appointments are accepted in the department.

\section{Subject Selection}

The following study was done only on walk-in patients on their first visit. Patients who had scheduled their appointments with specific doctors by telephone were excluded from the study. This was done to avoid any preexisting bias created by making an appointment with surgeons of either gender or due to prior visits to surgeons of either gender. Patients who had been referred to a particular surgeon from peripheral centers were also excluded from the study. No patient identifying information was collected. The study protocol was approved by the Institutional Ethical Committee and a signed informed consent was obtained from all the subjects.

\section{Data Collection}

Data was collected from December 2016 to April 2017. Standardized proformas were kept in the waiting lobby of the department. All subjects taking part in the study were asked to fill the proforma before the beginning of their consultation with the doctors. This was done to avoid any bias that may occur after meeting the treating doctor. Instructions were available on the brochure to the subjects that the completed proformas were to be put in a preassigned collection box kept in the lobby. Audiological support in the form of prerecorded instructions in the local language was available for illiterate subjects in both male and female voices. To avoid bias, no male or female staff/doctors were involved in the distribution or collection of brochures.

\section{Pro Forma}

The brochures were available in both English and in the local language (Hindi). It clearly stated that the study was completely voluntary, and its results are confidential. It also stated that the subjects may choose to not take part in the study and this would have no effect on their treatment. The following subspecialties in ORL-HNS were included-otology, laryngology, pediatric ORL, and head and neck oncosurgery.
There were two parts in the proforma-demographic details and gender preference. The following proforma was utilized for data collection (-Supplementary Material).

\section{Statistical Analysis}

Non-parametric statistics were used for the categorical variables analyzed. The Chi-square test was used to compare the effects of age, gender, education, employment and place of residence on the subjects' preference. The rejection level for null hypothesis was fixed at 5\% ( $p<0.05)$. The analysis was performed using the software SPSS version 17 (SPSS, Inc., Chicago, IL, USA).

\section{Results}

\section{Quantitative Data}

A total of 1,112 subjects took part in the study. Incomplete and unintelligible forms were excluded from the study. The total number of subjects included in the final analysis was 1,089 . The subjects ranged in age from 18 to 74 years, with an average age of 41 years (standard deviation [SD], 14.12 years). Most of the subjects were males between the ages of $31-50$ years, college educated, belonging to urban areas and employed at the time of study. The rest of the demographic details of the subjects have been tabulated in - Table 1 .

Among the four subspecialties analyzed, - Table 2 depicts the preference of the subjects in each subspecialty. In our study, on an average, $40.375 \%$ of the participants showed gender preference when asked to choose between two

Table 1 Demographic details

\begin{tabular}{|l|l|}
\hline Gender & N (\%) \\
\hline Male subjects & $675(61.98 \%)$ \\
\hline Female subjects & $414(38.01 \%)$ \\
\hline Place of residence & $324(29.75 \%)$ \\
\hline Rural area & $765(70.24 \%)$ \\
\hline Urban area & $207(19.00 \%)$ \\
\hline Age & $639(58.67 \%)$ \\
\hline $18-30$ years & $144(13.22 \%)$ \\
\hline $31-50$ years & $99(09.09 \%)$ \\
\hline $51-65$ years & $27(02.47 \%)$ \\
\hline 65 or more years & $279(25.61 \%)$ \\
\hline Educational level & $414(38.01 \%)$ \\
\hline Illiterate & $369(33.88 \%)$ \\
\hline School & $684(62.80 \%)$ \\
\hline College/Graduate & $90(08.26 \%)$ \\
\hline Postgraduate & $315(28.92 \%)$ \\
\hline Current employment status & \\
\hline Not employed & \\
\hline Employed & \\
\hline Retired & \\
\hline
\end{tabular}


Table 2 Gender preference of subjects in different subspecialties of otorhinolaryngology

\begin{tabular}{|l|l|}
\hline Otology & N (\%) \\
\hline Prefer male doctors & $171(15.70 \%)$ \\
\hline Prefer female doctors & $171(15.70 \%)$ \\
\hline No gender preference & $747(68.59 \%)$ \\
\hline Laryngology & $207(19.00 \%)$ \\
\hline Prefer male doctors & $279(25.61 \%)$ \\
\hline Prefer female doctors & $603(55.37 \%)$ \\
\hline No gender preference & $180(16.52 \%)$ \\
\hline Pediatric otolaryngology & $342(31.40 \%)$ \\
\hline Prefer male doctors & $567(52.06 \%)$ \\
\hline Prefer female doctors & $288(26.44 \%)$ \\
\hline No gender preference & $135(12.39 \%)$ \\
\hline Head and neck oncology & $666(61.15 \%)$ \\
\hline Prefer male doctors & \\
\hline Prefer female doctors & \\
\hline No gender preference &
\end{tabular}

equally skilled, equally reputable doctors with similar experience level. Based on subspecialty, $30.14 \%$ of the subjects showed gender preference for otological surgeries. Other subspecialties, like pediatric ORL (47.92\%), laryngology ( $44.61 \%$ ) and oncosurgery (38.83\%), had a higher proportion of subjects showing gender preference. In fact, pediatric ORL had the maximum number of subjects with gender preference, while otology showed the least. Among each subspecialty, female doctors were most frequently preferred for pediatric ORL, while male doctors were most frequently preferred for head and neck oncology.

Each subspecialty was further analyzed separately by comparing subjects who did show gender preference with those who did not ( - Table 3 ).
Table 4 List of some of the reasons provided by the subjects for showing male gender preference in any subspecialty in otorhinolaryngology and head and neck surgery

\begin{tabular}{|l|}
\hline Reasons for showing preference for male surgeons \\
\hline More stamina \\
\hline Fearless \\
\hline Consistent \\
\hline Less sensitive \\
\hline Confident \\
\hline Better surgeon \\
\hline Competent \\
\hline Examines patients better \\
\hline More experienced \\
\hline Trustworthy/Higher level of belief in him \\
\hline Higher level of patience \\
\hline Superior professional skills \\
\hline Expert \\
\hline Bad experience with female surgeons in past \\
\hline I am a male. So, I can talk openly with a male doctor \\
\hline
\end{tabular}

\section{Qualitative Data}

The participants were also asked to mention the reason for their choices. Some of the reasons provided by the subjects have been tabulated below (-Tables 4-6).

\section{Discussion}

The gender of a surgeon has a significant bearing on the patients' preference in situations in which health concerns are intimate, or gender related. Various studies have been conducted on patients undergoing urological procedures, ${ }^{1}$ gynecological surgeries, ${ }^{4}$ breast reconstruction, ${ }^{5}$ and gender affirmation surgeries ${ }^{2}$ to analyze whether significant gender preference exists among patients when choosing the treating

Table 3 Comparison of various factors (age, gender, place of residence educational status and employment status) between groups of patients who showed and did not show gender bias while choosing a surgeon in different subspecialties

\begin{tabular}{|c|c|c|c|c|c|}
\hline Sub-specialty & $\begin{array}{l}\text { Age } \\
\text { (Chi-square } \\
\text { statistic, } \\
p \text { value) }\end{array}$ & $\begin{array}{l}\text { Gender } \\
\text { (Chi-square } \\
\text { statistic, } \\
p \text { value) }\end{array}$ & $\begin{array}{l}\text { Place of residence } \\
\text { (Chi-square statistic, } \\
p \text { value) }\end{array}$ & $\begin{array}{l}\text { Educational status } \\
\text { (Chi-square statistic, } \\
p \text { value) }\end{array}$ & $\begin{array}{l}\text { Employment status } \\
\text { (Chi-square statistic, } \\
p \text { value) }\end{array}$ \\
\hline Otology & $\begin{array}{l}24.1344 \\
p=0.000023\end{array}$ & $\begin{array}{l}9.5557 \\
p=0.001993\end{array}$ & $\begin{array}{l}4.7419 \\
p=0.0294\end{array}$ & $\begin{array}{l}1.2013 \\
p=0.7526\end{array}$ & $\begin{array}{l}18.1542 \\
p=0.000114\end{array}$ \\
\hline Laryngology & $\begin{array}{l}17.408 \\
p=0.000582\end{array}$ & $\begin{array}{l}12.1631 \\
p=0.000487\end{array}$ & $\begin{array}{l}133.2898 \\
\mathrm{p}<0.00001\end{array}$ & $\begin{array}{l}42.1788 \\
\mathrm{p}<0.00001\end{array}$ & $\begin{array}{l}68.0011 \\
\mathrm{p}<0.00001\end{array}$ \\
\hline Pediatric ORL & $\begin{array}{l}20.9461 \\
p=0.000108\end{array}$ & $\begin{array}{l}1.1424 \\
p=0.285\end{array}$ & $\begin{array}{l}\text { 64.8512, } \\
\mathrm{p}<0.00001\end{array}$ & $\begin{array}{l}48.7679 \\
\mathrm{p}<0.00001\end{array}$ & $\begin{array}{l}47.4847 \\
\mathrm{p}<0.00001\end{array}$ \\
\hline $\begin{array}{l}\text { Head and neck } \\
\text { oncosurgery }\end{array}$ & $\begin{array}{l}21.9092 \\
p=0.000068\end{array}$ & $\begin{array}{l}0.0811 \\
p=0.7758\end{array}$ & $\begin{array}{l}33.1142 \\
p<0.00001\end{array}$ & $\begin{array}{l}13.5077 \\
p=0.003658\end{array}$ & $\begin{array}{l}3.8889 \\
p=0.143063\end{array}$ \\
\hline
\end{tabular}


Table 5 List of some of the reasons provided by the subjects for showing female gender preference in any subspecialty of otorhinolaryngology and head and neck surgery

\begin{tabular}{|l|}
\hline Reasons for showing preference for female surgeons \\
\hline Soft spoken \\
\hline Caring \\
\hline Gentle \\
\hline Knows children better \\
\hline Merciful \\
\hline Has more patience than her male counterparts \\
\hline Empathetic \\
\hline Delicate hands \\
\hline Better listener \\
\hline Sympathetic \\
\hline Handles children better \\
\hline Cares for children \\
\hline Children need to be handled with patience \\
\hline Treats patients better \\
\hline I am a female. So, I would be more comfortable. \\
\hline
\end{tabular}

Table 6 List of some of the reasons provided by the subjects for showing no gender preference in any subspecialty in otorhinolaryngology and head and neck surgery

\begin{tabular}{|l|}
\hline Reasons for showing no gender preference \\
\hline Skill matters more than gender \\
\hline Educational qualifications matter \\
\hline I have liberal thoughts \\
\hline Experience matters \\
\hline Gender discrimination is unacceptable \\
\hline Gender of the doctor is not important \\
\hline Both male and female doctors can be equally good \\
\hline A responsible doctor should be chosen \\
\hline A doctor is a doctor \\
\hline Empathy of a doctor is important. \\
\hline Only skill and competence are a prerequisite \\
\hline
\end{tabular}

surgeon. Some studies have also shown that female patients are known to prefer female surgeons, while male patients prefer male surgeons. However, an analysis of gender preference in a gender-neutral specialty, such ORL-HNS, has never been done. This is the first study of its kind to analyze the effect of the surgeon's gender on patients' choice in the field of ORL-HNS.
Understanding the reasons behind gender preference is vital. This difference could be a reflection of societal prejudices attached to each gender due to its predefined role in the society. For instance, some subjects who stated their preference for a female surgeon to handle pediatric operations were of the opinion that female surgeons are more patient and caring and, therefore, would handle children better. Some subjects who preferred male surgeons for oncosurgery found male surgeons to be stronger, fearless and having more stamina. Previous experiences of the subjects with other surgeons of the same or other specialty may also have affected our findings.

Understanding the gender preference of the patients will help surgeons to introspect, identify possible shortcomings and develop subspecialty specific body language and interpersonal skills to make their patients more comfortable. Additionally, consideration of these factors is also essential in this patient-driven market of health care so that surgeons are able to portray themselves in a more patient-friendly manner conducive to each subspecialty.

\section{Conclusion}

Otorhinolaryngology and head and neck surgery, as a branch, has long been considered a gender-neutral specialty. However, when given an option to choose between two equally qualified and reputable surgeons of either gender, patients of various subspecialties of ORL-HNS showed considerable gender preference while selecting their treating surgeon.

Source of Financial Support

None.

Conflict of Interest

The authors declare that there are no conflicts of interest. The authors have no financial or personal relationship with other people or organizations that could inappropriately influence this work.

\section{References}

1 Oberlin DT, Vo AX, Bachrach L, Flury SC. The Gender Divide: The Impact of Surgeon Gender on Surgical Practice Patterns in Urology. J Urol 2016;196(05):1522-1526

2 Ettner R, Ettner F, White T. Choosing a Surgeon: An Exploratory Study of Factors Influencing Selection of a Gender Affirmation Surgeon. Transgend Health 2016;1(01):124-128

3 Naidu NS, Patrick PA. The influence of career stage, practice type and location, and physician's sex on surgical practices among board-certified plastic surgeons performing breast augmentation. Aesthet Surg J 2011;31(08):941-952

4 Childs AJ, Friedman WH, Schwartz MP, Johnson M, Royek AB. Female patients' sex preferences in selection of gynecologists and surgeons. South Med J 2005;98(04):405-408

5 Groutz A, Amir H, Caspi R, Sharon E, Levy YA, Shimonov M. Do women prefer a female breast surgeon? Isr J Health Policy Res 2016;5:35 